\title{
Amplification of Single Walled Carbon Nanotubes from Designed Seeds: Separation of Nucleation and Growth
}

\author{
Douglas Ogrin,${ }^{\dagger}$ Robin E. Anderson,${ }^{\dagger}$ Ramon Colorado, Jr., ${ }^{\dagger}$ Benji Maruyama, ${ }^{\ddagger}$ Mark J. Pender, ${ }^{\dagger}$ \\ Valerie C. Moore,${ }^{\dagger}$ Sean T. Pheasant, ${ }^{\dagger}$ Laura McJilton,${ }^{\dagger}$ Howard K. Schmidt,$\dagger$ \\ Robert H. Hauge, ${ }^{\dagger}$ W. Edward Billups,${ }^{\dagger}$ James M. Tour,${ }^{\dagger}$ Richard E. Smalley,$\dagger$ \\ and Andrew R. Barron ${ }^{\dagger *}$
}

Richard E. Smalley Institute for Nanoscale Science and Technology, Carbon Nanotechnology Laboratory, and Department of Chemistry, Rice University, Houston, Texas 77005

And

Materials and Manufacturing Directorate, Air Force Research Laboratory, Wright Patterson AFB, Ohio 45433

Supplementary Material 


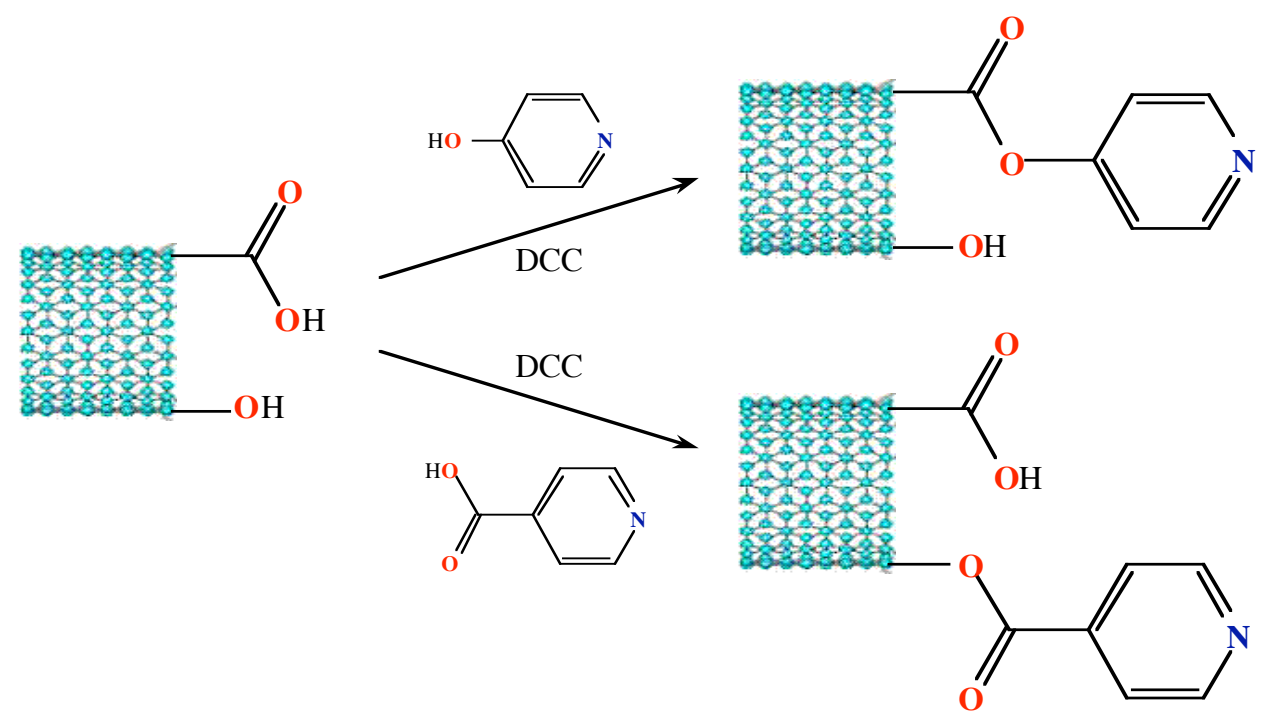

Scheme S1. Pyridine functionalization of SWNT ends via DCC catalyzed coupling reaction with 4hydroxypyridine or isonicotinic acid. 


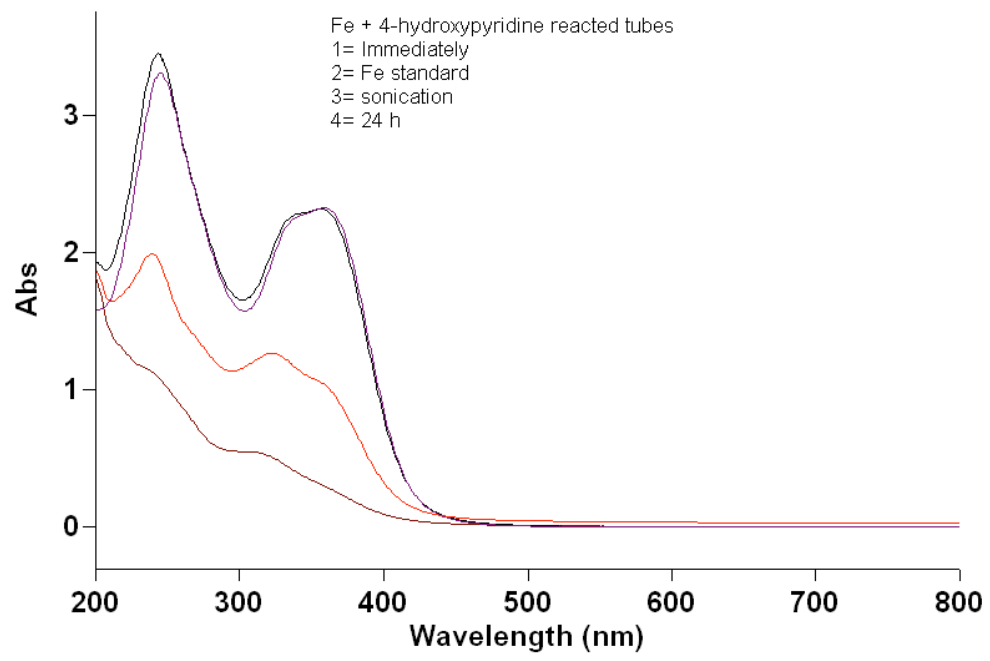

Figure S1. UV-vis spectra of $\mathrm{Fe}\left(\mathrm{NO}_{3}\right)_{3}$ in the presence of 4-hydroxypyridine coupled to SWNTs (DD-SWNT-py). 
(a)



(b)

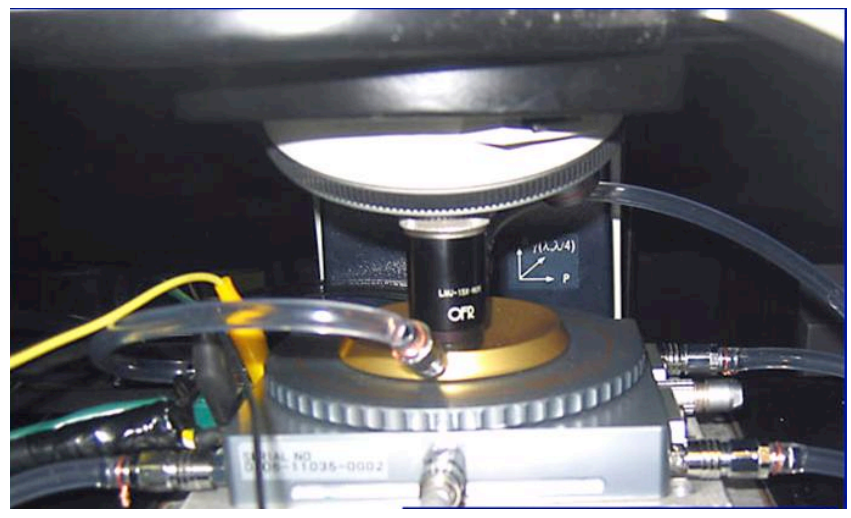

(c)

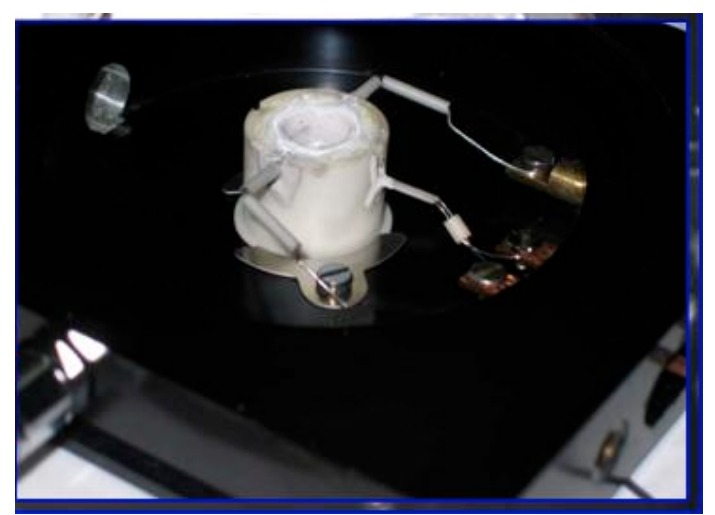

Figure S2. Pictures of the hot stage used for DD-SWNT-py-FeMoC growth runs: (a) entire apparatus, (b) close up of the hot stage, and (c) close-up of the button heater. 

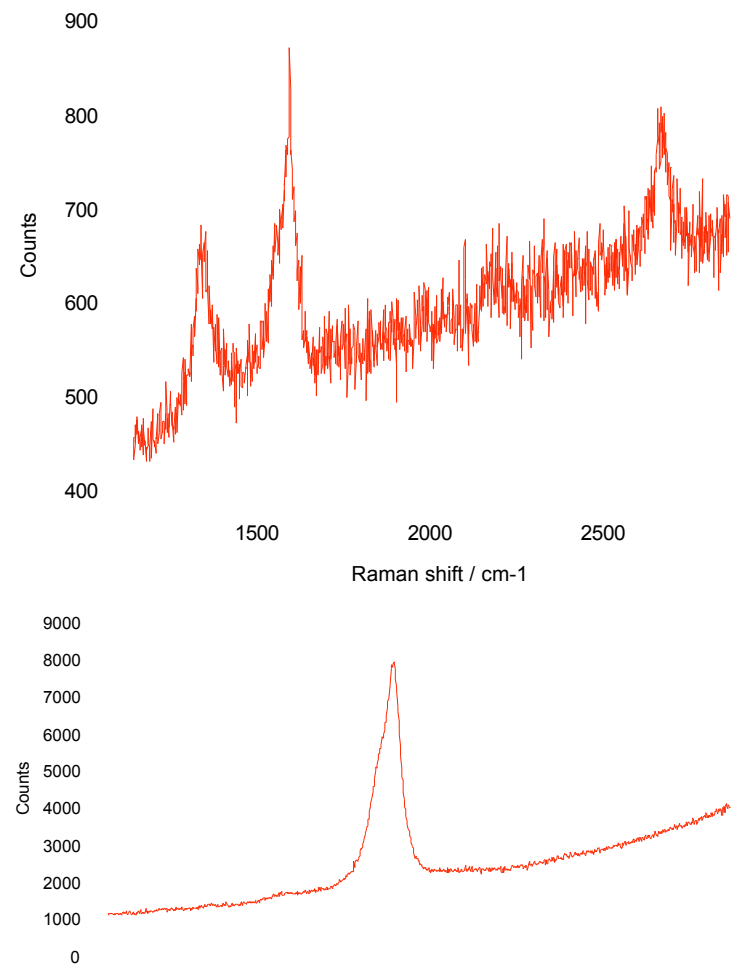

1000110012001300140015001600170018001900200021002200 Raman shift / cm-1

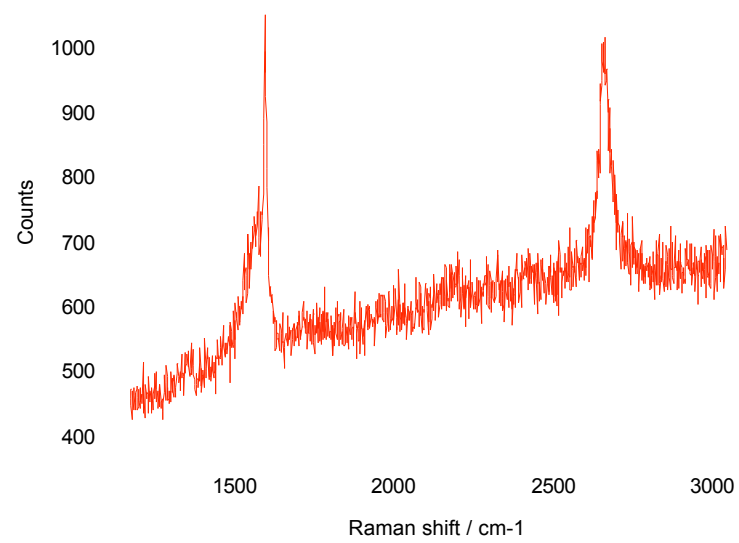

Figure S3. Raman spectra of DD-SWNT-py-FeMoC (top) at room temperature, (middle) after heating to $200{ }^{\circ} \mathrm{C}$, and (bottom) after growth. 


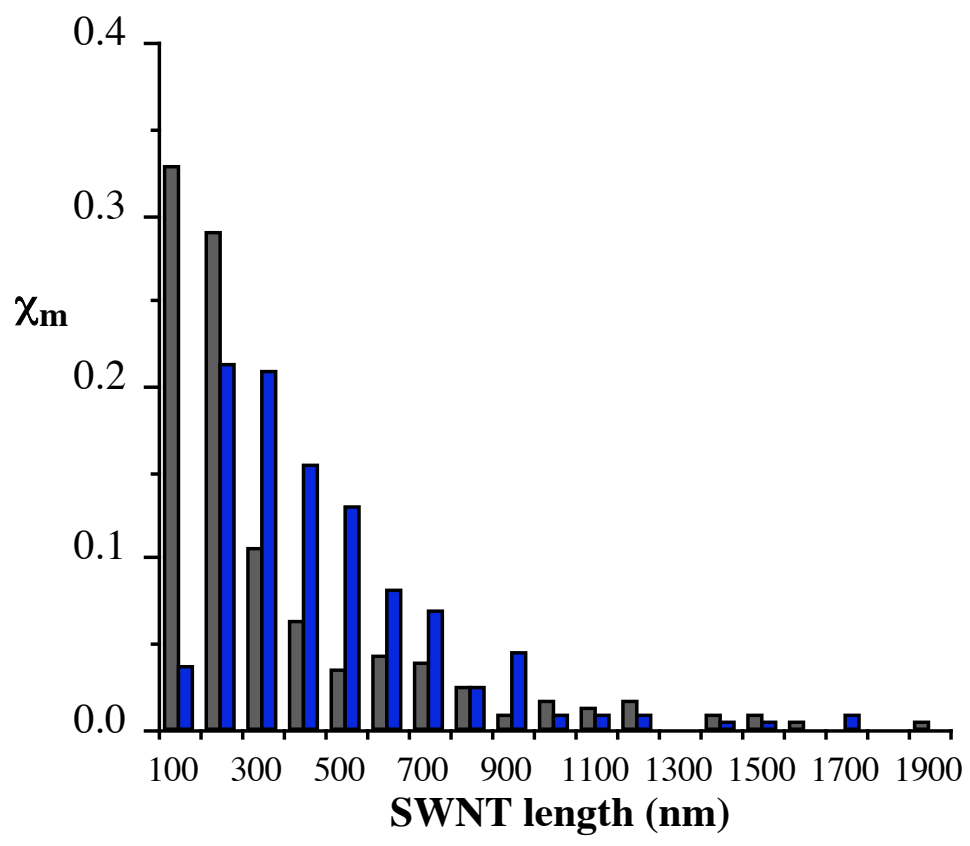

Figure S4. Plot of SWNT length after growth $(\square)$ as compared the DD-SWNT-py-FeMoC "SWNT-cat" seeds $(\square)$ showing the lack of change in the length of the longer (> $1000 \mathrm{~nm})$ "SWNT-cat" suggesting that these are inactive. 


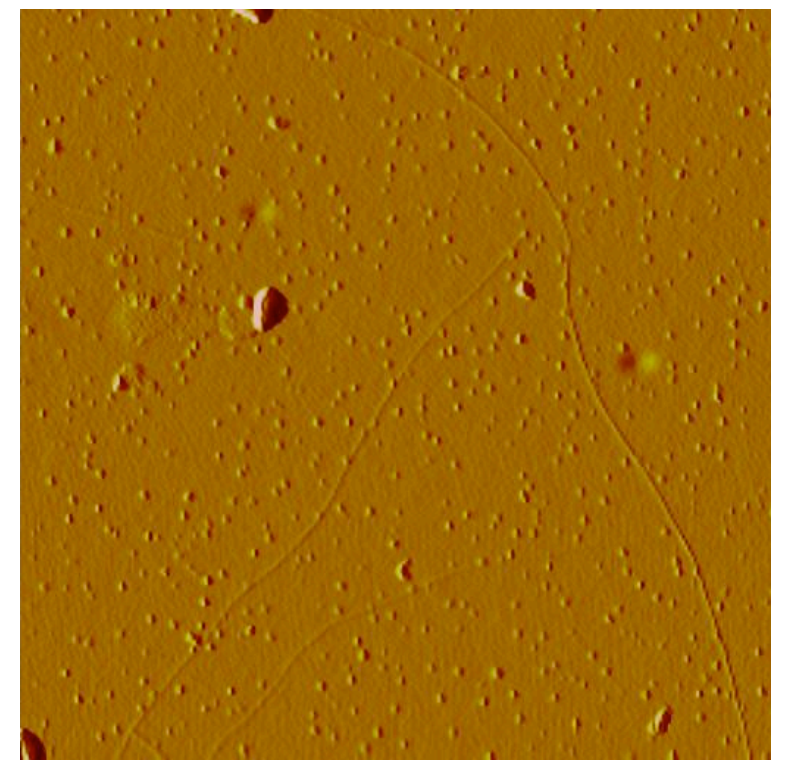

Figure S5. AFM image of VLS grown SWNTs from FeMoC:pyz (1:25) showing the pore growth yield from the catalyst in the absence of a seed. Image is $2 \mu \mathrm{m} \times 2 \mu \mathrm{m}$. From our prior results: D. Ogrin, R. Colorado, Jr., B. Maruyama, M. J. Pender, R. E. Smalley, and A. R. Barron, Dalton Trans., 2006, 229-233. 
(b)

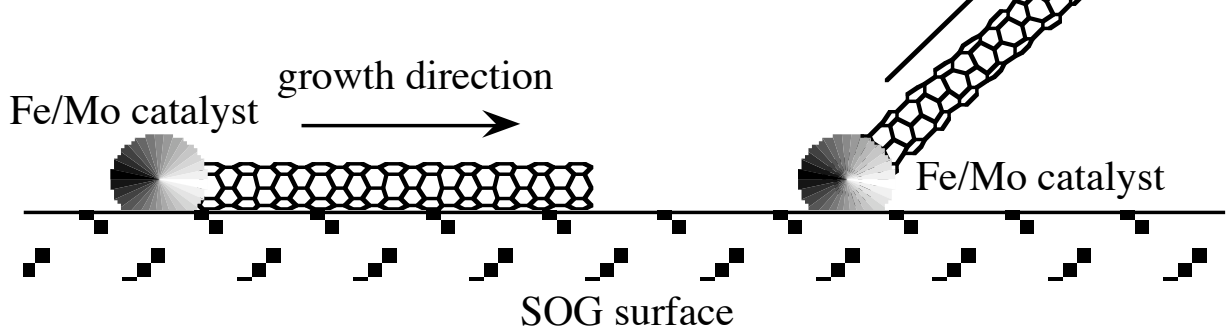

Figure S6. Schematic representation of supported catalyst SWNTs growth in which the SWNT grows parallel to the surface (a) or out from the surface (b). Adapted from D. Ogrin, R. Colorado, Jr., B. Maruyama, M. J. Pender, R. E. Smalley, and A. R. Barron, Dalton Trans., 2006, 229-233. 